\title{
RESPONSIBLE INVESTMENTS IN A DEVELOPING COUNTRY: CASE STUDY OF A BOLIVIAN PILOT EXPERIENCE
}

\section{Ricardo Nogales Carvajal, Pamela Córdova Olivera y Laura C. García Sobral}

\begin{abstract}
This document presents a pilot experience for the development of Socially Responsible Investment practices in Bolivia that has involved 53 agricultural and agro industrial business from all over the country. This experience is grounded on the need of complementing the micro financial system in Bolivia, in order to better cope with the importance of small-scaled rural businesses and reinforce its capability for promoting a sustainable, socially inclusive economic development process, through the capital market. This pilot builds upon three cores aspects that have been identified as priorities in the Bolivian context: i) the legal foundation of these alliances, proposing modifications to the current legal bodywork, in order to create the Funds for Social Development and their managers, the Investment Societies for Development; ii) the development of Factor Analysis based techniques of risk assessing for investors to be able to engage in alliances with rural businesses, through the creation and coimplementation of specific business plans leading to the achievement of financial and social realistic goals and iii) strategies for monitoring and evaluating these alliances, in order to create and systematize empirical evidence that can lead to the constant perfection of these kind of financial interventions.
\end{abstract}

Keywords: Responsible Investing, Factor Analysis, Investment Societies for Development, Funds for Social Development, Risk Assessment. 